\title{
IMPORTANCIA DE LA LINGÜÍSTICA PRAGMÁTICA EN LA HERMENÉUTICA BÍBLICA ${ }^{1}$
}

\author{
Massimo Grilli \\ Pontificia Università Gregoriana (Roma) \\ ma_grilli@hotmail.com
}

Resumen: Partiendo del presupuesto de que la Biblia es "Palabra de Dios en lenguaje humano" (DV 12), este artículo trata sobre una hermenéutica bíblica en clave comunicativa. El estudio se divide en dos partes: en la primera (n. 1 y 2), de carácter fundamentalmente teórico, se analizan los diversos modelos de comunicación humana y su impacto en la hermenéutica bíblica; en la segunda (n. 3), se estudia desde una perspectiva pragmática el texto de las "bienaventuranzas" de Mt 5,1-12, analizando sobre todo los actos lingüísticos del texto. Se trata tan solo de un ejemplo entre las diferentes aplicaciones que la pragmática puede tener en el contexto bíblico latinoamericano y en otros ámbitos.

Palabras clave: Lingüística pragmática. Lenguaje bíblico. Bienaventuranzas. Hermenéutica latinoamericana.

\section{Relevance of Pragmalinguistics in Biblical Hermeneutics}

Abstract: Beginning from the supposition that the Bible is "the word of God in human language" (cf. DV 12), the article concerns biblical hermeneutics under the communicative aspect. The study is divided in two parts: in the first (n.1 and 2), which is of a primarily theoretical character, different models of human communication are analyzed, along with the impact that they have on biblical hermeneutics. In the second (n.3), the text of the "Beatitudes" of Matthew 5:1-12 is studied under

1 Agradezco a Santos Rosendo Cruz Piñín (Perú), que ha traducido este artículo del italiano, y a María Verónica Talamé (Argentina), que ha revisado la traducción. El texto de referencia para toda esta presentación será el reciente volumen de M. GRILLI - M. GuIDI - E. OBARA, Comunicación y pragmática en la exégesis bíblica (Evangelio y Cultura 6), Estella 2018. 
the pragmatic perspective, emphasizing above all the analysis of the speech acts contained in the passage. Only this one example is treated here, among the many possible applications that the pragmatic approach could have in the biblical context of Latin America and elsewhere.

Keywords: Pragmatic Linguistics. Biblical language. Beatitudes. Latin America Hermeneutics.

La pragmalingüística parte del presupuesto de que escuchar y/o leer un texto significa entrar en un proceso comunicativo. Se entabla así un diálogo cuyos protagonistas son el texto y la comunidad de lectores. Sobre la base de esta precomprensión y a partir de los años sesenta, los estudios de la teoría de la comunicación han subrayado con fuerza la convicción de que el funcionamiento de un texto (ya sea oral o escrito) no se explica considerando solo el momento generativo, sino también el momento receptivo; porque conlleva aspectos que no se pueden explicar solo en términos de contenido, sino que deben entenderse en términos funcionales. Así pues, los textos no solo se explican por lo que significan, sino por lo que producen. Esta convicción ha dado origen a una proliferación de teorías sobre la relación entre "autor-lector", que se insertan muy bien en el debate hermenéutico latinoamericano, donde el pueblo creyente que lee la Biblia tiene un rol competente e imprescindible.

Para su mejor comprensión, este artículo estará dividido en tres secciones: el proceso comunicativo y su dimensión pragmática (I), el proceso comunicativo - con su dimensión pragmática- y su aplicación en la hermenéutica bíblica (II), y un ejemplo bíblico: las bienaventuranzas y la pragmática (III).

\section{El proceso comunicativo y su dimensión pragmática}

\subsection{Los modelos de comunicación}

Los estudiosos del lenguaje no concuerdan en la definición y en la descripción del proceso comunicativo; sin embargo -y aunque en forma reducida-, se podrían identificar tres modelos de comunicación ${ }^{2}$ :

2 Sigo aquí substancialmente a BERGE, "Communication”. 
El primer modelo es el más sencillo y fue definido como "el modelo lineal" (the conduit model). En este, el lenguaje se concibe como un "canal" mediante el cual el mensaje se transmite desde el emisor al receptor. Por un lado, tenemos a aquel que establece ciertos contenidos, les da la mejor forma posible -mediante un trabajo de "codificación"-y se los transmite al destinatario. Por otro lado, tenemos al destinatario del mensaje, que cumple una función inversa: a través de un ejercicio de "decodificación", procede desde el exterior hacia el interior. El mensaje recibido se puede descifrar cuando se conocen los códigos en los cuales fue codificado. En este modelo, la comunicación fluye en una sola dirección: del emisor al destinatario, pero sin prestar atención a la reacción de este último. Solo se considera la intentio auctoris. No se atribuye al receptor ningún aporte particular más que el de reconocer la intención del que envía el mensaje. Para este modelo, lo esencial es que el emisor tenga una cierta intención de informar o convencer al destinatario y que el mensaje llegue a su destino ${ }^{3}$. El papel del receptor es, por tanto, puramente pasivo.

El segundo modelo podría definirse como "modelo de reacción"; porque, a diferencia del modelo lineal, también otorga una función activa al receptor del mensaje. Este no es visto simplemente como un receptor meramente pasivo, al que solo le corresponda la tarea de reconocer la intencionalidad del emisor, sino como un interlocutor activo que, una vez recibido el mensaje, responde y/o reacciona a las motivaciones del remitente. Este modelo es ciertamente más completo que el primero, porque libra del solipsismo, pero sigue sin convencer del todo. Sugiere un tipo de comunicación en la que se dan diferentes momentos, durante los cuales cada interlocutor es alternativamente emisor o receptor. Al mensaje de uno corresponde la reacción del otro y viceversa. En otras palabras, a pesar de su carácter interactivo, este modelo aparece igualmente rígido. La presentación del siguiente modelo lo hará entender aún mejor.

El tercer modelo se conoce como el "modelo circular" o "dialógico". Comparte con el segundo modelo la convicción de que la comunicación es un evento interactivo, pero considera a los dos interlocutores en colaboración simultánea con las operaciones necesarias. El emisor y el receptor no actúan sucesivamente; de modo que la decodificación y la respuesta no se producen después de que se emite el mensaje, sino al mismo tiempo. Recibir, deco-

3 Por eso, este modelo fue considerado como el más cercano al de la retórica clásica. 
dificar y responder forman parte de un proceso que acontece simultáneamente, de modo que el receptor es al mismo tiempo emisor y ambos aportan a la construcción del mensaje. En otras palabras, la comunicación no es algo que uno hace al otro, sino un proceso que uno hace con el otro. En esta línea, fue sobre todo Grice quien destacó el hecho de que cualquier intercambio comunicativo se juega de hecho en la interacción y a través de los mecanismos inferenciales.

Este último modelo parece ser el más adecuado para explicar la comunicación: se trata de una forma circular o dialógica que supone como base de la interacción comunicativa un principio de cooperación. Este es el modelo que se profundizará a continuación, dejando claro desde el principio que hablamos de "modelo dialógico" en el ámbito de la lectura de un texto: el punto de partida de lo que se desarrollará a continuación tiene como presupuesto el diálogo texto-lector ${ }^{4}$.

\subsection{El modelo dialógico}

Es universalmente conocida la afirmación que hizo Roland Barthes en 1967, suscitando una serie de reacciones que persisten hasta el día de

${ }^{4}$ El texto escrito y el texto hablado deben considerarse dos variantes funcionales de un único lenguaje, pero es evidente que cada sistema está dotado de su propia especificidad y responde a diferentes necesidades. Trataremos de comparar el sistema oral con el sistema escrito con el objeto de comprender mejor el proceso de comunicación entre el autor de un texto escrito y el lector: a) El medio. El texto oral es un texto vivo, fragmentado, con enunciados que son en su mayoría breves y supeditados a ajustes continuos de formulación, de explicación, de repeticiones, etc. El texto escrito, en cambio, es estratificado, permanente, conciso, pero al mismo tiempo provisto de una mayor complejidad lexical y sintáctica. b) El contexto. Un texto oral presenta características contingentes que lo vinculan a un interlocutor específico (o a un grupol y a un contexto espacio-temporal bien definido. En cambio, el texto escrito puede prever lectores y contextos situacionales distintos del "aquí" y "ahora". Incluso puede entrañar una cierta "distancia comunicativa" de varios tipos: situacional, cultural, etc. c) La función. Un texto oral y un texto escrito pueden tener los mismos objetivos y, por ende, tener la misma función. Sean textos narrativos, descriptivos, argumentativos o normativos, pueden perseguir los mismos fines, tanto en un contexto oral como escrito. De estos breves indicadores resulta natural que un texto escrito, donde la historia ha cristalizado en formas expresivas fijas, presente mayores dificultades de interpretación que un texto oral. En una comunicación verbal hecha de forma oral, el tono de la voz, las expresiones del rostro, los gestos... son indicios que ayudan considerablemente a comprender las funciones de un determinado texto; mientras que en un texto escrito el proceso es más articulado y ciertamente más laborioso. 
hoy: "El nacimiento del lector se paga con la muerte del autor" 5 . El escritor y ensayista español Enrique Vila-Matas señalaba recientemente que obviamente Barthes estaba exagerando, pero que de todos modos hay una evidente necesidad de redefinir los términos del contrato moral entre autor y lector ${ }^{6}$. En la misma década de los sesenta, G. Gadamer -en su libro Wahrheit und Methode (1960) - entraba en el debate con su propuesta hermenéutica acerca de la comprensión de una obra en estrecha relación con la experiencia personal histórico-existencial del lector. Es también de aquellos años la obra de H. R. Jauss, Literaturgeschichte als Provokation der Literaturwissenschaft (1967), quien fomentó la discusión acerca de la centralidad de la recepción, frente a las metodologías centradas en el texto (tanto las de tipo formalista como las de tipo estructuralista) que dominaban los estudios literarios de aquel período. Sin embargo, ya Jean-Paul Sartre -en su ensayo Qu'est que la littérature (1948)- había definido el objeto literario con una hermosa metáfora: "un extraño trompo que no existe sino cuando está en movimiento. Para hacerlo nacer requiere un acto concreto llamado lectura y dura tanto cuanto la lectura puede durar"7.

Ahora bien, sobre la base de esta nueva percepción y de la importancia del polo receptor para la lectura de un texto, es decir, sobre la base del modelo dialógico descrito anteriormente, ¿cuáles son los nuevos términos en los que se plantea el contrato entre autor y lector? Presentaremos los nuevos términos de este contrato a los que se ha llegado en virtud de tres cambios: el paso del paradigma "semántico" al "pragmático"; el paso del paradigma "modelístico" al "cooperativo", y el paso de la "cohesión gramatical y sintáctica" a la "estrategia textual".

\section{Desde el paradigma "semántico" al "pragmático"}

$\mathrm{Al}$ analizar el contexto de un enunciado en la acepción que este tiene en la semántica tradicional y en el que tiene en la pragmática, notamos una divergencia considerable: el contexto semántico "fija la identidad del hablante y de los interlocutores, del tiempo y del lugar de enunciación, y

5 El ensayo "La mort de l'Auteur" fue publicado primeramente en inglés ("The Death of the Author"), en la revista americana Aspen 5-6 (1967), y el año siguiente (1968) en francés, en la revista Manteia. Tomo la cita de la colección Le bruissement de la langue, Paris 1984, 61.

6 Del diario italiano /l Sole 24 ore, 2 de octubre de 2011.

7 Sartre, Che cos'è la letteratura, 33. 
así sucesivamente...", mientras que el contexto pragmático "está constituido por el conjunto de creencias, intenciones, propósitos de los interlocutores..." ${ }^{8}$. También podría decirse que en la semántica tradicional el contexto está vinculado a lo que se dice, mientras que en la pragmática tiene relación con lo que se pretende comunicar y, por lo tanto, es el resultado de una cooperación interpretativa entre el emisor de un enunciado y su intérprete. En el contexto -entendido en sentido comunicativo y pragmático- tienen preeminencia inmediatamente "las relaciones entre los interlocutores... respecto a sus conocimientos previos del tema sobre el cual se ocupan o de sus premisas" y en definitiva "todos los condicionamientos socioculturales a los cuales los hablantes están sujetos" ". Por ejemplo, un breve mensaje como: "está lloviendo a cántaros" -que semánticamente significa solo aquello que dicen las palabras- pragmáticamente evoca varios posibles escenarios (o contextos). Puede hacer referencia a un estudiante que en su habitación se enoja y dice: "¿Qué rabia, ahora que había decidido hacer una caminata, tengo que quedarme a estudiar!" o a una mamá que en la casa le ordena a su hijo: “iAhora no sales de casa para jugar!”, etc. Así pues, pragmáticamente, el contexto puede entenderse como una estructura hermenéutica a través de la cual un lector organiza y entiende los diversos elementos textuales.

En este ámbito contextual, la función de la pragmática es doble ${ }^{10}$ :

(1) Por un lado, se ocupa de la influencia del contexto sobre la palabra y, en consecuencia, de las informaciones sobre las situaciones del discurso que un receptor debe tener en cuenta para interpretar correctamente el lenguaje del texto. Aquí se trata de "hacer palabras con las cosas"

(2) Por otro lado, estudia la influencia de la palabra sobre el contexto y, por tanto, de cómo los hablantes se sirven del lenguaje para cambiar la situación del discurso, y en particular para influir en las creencias y en las acciones de sus interlocutores. Aquí se trata de "hacer cosas con las palabras" 12 .

8 Bianchi, Pragmatica, 52.

9 Segre, Avviamento, 203.

10 Bianchi, Pragmatica, 11.

11 Como se titula el segundo capítulo de la obra de BIAnchI, Pragmatica.

12 Título del tercer capítulo de BIANCHI, Pragmatica. 
Desde el paradigma "modelístico" al "cooperativo"

La primera premisa del contrato autor-lector en el nuevo modelo comunicativo se puede describir como el paso de un "paradigma modelístico" -en el que prevalecía el código y la comunicación se concebía como codificación y decodificación de mensajes- a un "paradigma inferencial", donde la comunicación está marcada por una relación cooperativa entre la manifestación y el reconocimiento de las intenciones, entre la expresión y la recepción.

En efecto, la relación establecida en la tríada autor-texto-lector ha sido revisada y releída a la luz de una perspectiva más dinámica y se ha afianzado la convicción del papel fundamental de la recepción. Esto significa que el interés se ha ido focalizando principalmente en la figura del lector, ya sea como destinatario, ya sea como sujeto, no solo en la vivencia del mensaje, sino también en la co-creación del texto literario. La oscilación desde la intentio auctoris (propia del método histórico-crítico) a la intentio operis hasta la intentio lectoris ha conocido (y todavía sigue conociendo) fases confusas e irregulares. Sin embargo, en las últimas décadas se ha arraigado cada vez más la convicción de que la función de un texto no puede prescindir de la participación del polo receptor y se está pasando cada vez más del paradigma tradicional, en el que la determinación del sentido de las proposiciones era encomendado a la semántica, a un modelo que ve siempre necesario el aporte pragmático.

En este sentido, una contribución decisiva al respecto es la de Grice ${ }^{13}$, con las llamadas "implicaturas conversacionales" (conversational implicatures). Grice propone que el interlocutor, presuponiendo en el remitente del mensaje una voluntad real de comunicar algo significativo, activa una serie de mecanismos inferenciales que dan razón también de aquellas implicaturas o contenidos implícitos que de hecho no llegan a una codificación lingüística directa y que hacen que una respuesta a veces parezca una violación de las máximas conversacionales. Un intercambio de ideas en el plano de la experiencia cotidiana demuestra claramente lo que queremos decir. El siguiente diálogo entre Pedro y Juan nos ayudará a entender lo que significan las implicaturas conversacionales:

Pedro: Marcos nos invitó a comer una pizza.

Juan: Tengo dolor de cabeza.

Pedro: ¡Pero mira que Isabel no está!

13 Para GRICE, Logica e conversazione, la interacción comunicativa se manifiesta sobre todo en el reconocimiento de las intenciones del hablante. 
En el diálogo, las palabras de Juan ("Tengo dolor de cabeza") encuentra una respuesta ("Pero mira que Isabel no está") que semánticamente rompe la regla de colaboración, porque no está relacionada con el enunciado precedente. Pero, en realidad, la respuesta de Pedro (“¡Pero mira que Isabel no está!") esconde un complejo movimiento inferencial que puede resumirse de esta manera: "Tú dices que tienes dolor de cabeza, pero dado que conozco tu profunda antipatía por Isabel, la novia de Marcos, creo que estás mintiendo y por lo tanto te digo que tu actitud es injustificada, iporque Isabel no estará presente!"). De este banal y cotidiano ejemplo se deriva lo siguiente:

(1) La comunicación no es un simple intercambio de paquetes ya confeccionados, sino que tiene signos de interactividad, negociabilidad... En definitiva, tiene características pragmáticas y no puramente semánticas. Informar, persuadir, orientar... son actos lingüísticos mediante los cuales el emisor actúa sobre el receptor no solamente en términos de "representación" del mundo, sino en términos de transformación del universo cognoscitivo.

(2) La comunicación supone, por un lado, la sinceridad y disponibilidad de los interlocutores tanto para hacerse entender como para encontrar los canales adecuados que hacen posible el intercambio; por el otro, para acoger los mensajes enviados, tratando de reconocer la unidad en lo superficial y en lo profundo, y para explicitar las implicaturas, llenar las lagunas, etc.

(3) El que emite la comunicación quiere hacerla funcional, asegurándose de minimizar las resistencias del destinatario, orientarlo hacia una interpretación que no provoque decodificaciones equivocadas...

(4) En el caso de que un enunciado resulte incompatible con una determinada situación comunicativa, el intérprete está llamado a ejercer una cooperación que active una serie de mecanismos inferenciales que puedan dar razón de la aparente violación de los códigos de interacción.

Desde la "cohesión gramatical y sintáctica" a la "estrategia textual"

U. Eco se inserta en el debate de los años sesenta con el libro Opera aperta (1962), pero sobre todo con Lector in fabula (1979) y con I limiti dell'interpretazione (1990). Principalmente, en estas dos últimas obras, reflexiona sobre la noción de "lector modelo", siguiendo a Wolfgang Iser, quien ya había indicado al "lector implícito" como estrategia textual ${ }^{14}$. Para

14 Cf. ISER, Der implizite Leser. 
el semiótico italiano, el "lector modelo" es un conjunto de condiciones textualmente establecidas que deben ser respetadas para que un texto sea comprendido y actualizado. Quien produce un texto inscribe -dentro del mismo texto- sus propias intenciones y prescribe un camino o múltiples caminos de lectura: crea así un perfil de "lector modelo", conforme a sus propias intenciones o exigencias. Estas intenciones inscriptas como huellas dentro del mismo texto configuran los procesos de cooperación entre autor y lector (cooperación interpretativa). Como afirma Eco:

El autor modelo es una voz que habla afectuosamente lo imperiosa u ocultamente) con nosotros, que nos quiere a su lado, y esta voz se manifiesta como una estrategia narrativa, como un conjunto de instrucciones que se nos imparten a cada paso y a las que debemos obedecer cuando decidimos comportarnos como lector modelo ${ }^{15}$.

El autor que escribe debe efectuar una serie de suposiciones respecto a los conocimientos y a las competencias de sus propios lectores. Por tanto, todo texto prefigura su "lector modelo", mejor aún, lo crea: "un texto es un artificio destinado a producir su lector modelo". Así pues, el autor no solo presupone un "lector modelo", sino que define sus competencias: elige un idioma, un patrimonio lexical, un universo enciclopédico... De esta manera, quedan planteados sus presupuestos estratégicos, a fin de que sus potenciales lectores correspondan a sus expectativas. Por tanto, un autor empírico permite una interpretación correcta cuando construye el texto de tal forma que pueda guiar al lector a través de estrategias más o menos restrictivas. Un lector real está invitado a seguir las estrategias que para él ha dispuesto el autor. De ese modo se produce la cooperación textual entre dos estrategias. En síntesis: el "autor modelo" como estrategia textual tiende a producir un determinado "lector modelo", por lo que el "autor modelo" y el "lector modelo" no son otra cosa que las dos caras de la misma estrategia narrativa.

Las categorías de "lector implícito" (Iser) y "lector modelo" (Eco) coinciden en el sentido de que en ambos casos se trata de estrategias "inscriptas en el texto"; sin embargo, no son exactamente iguales. Para Iser, los textos literarios están marcados por la indeterminación, no tienen una función comunicativa clara: implican un discurso "des-pragmatizado", que puede ser "re-pragmatizado" en el proceso de la lectura de maneras muy diferentes. Es decir, la perspectiva fenomenológica de Iser asigna al lector la tarea de cooperar e interactuar con el texto, pero en el sentido de estable-

15 Eco, Sei passeggiate, 18. 
cer un "punto de vista" que determine el significado del texto. En lo que respecta al "lector modelo", el punto de partida es otro, ya que la competencia del "lector modelo", su cooperación e interacción con el texto, se definen por el "imprint genético" del texto, su "marca de fábrica": el "lector modelo" ha sido creado con el texto, está impreso en él, disfruta de la libertad que el texto le concede ${ }^{16}$. Tal vez se podría decir que para Iser el "lector ficticio" retratado en el texto es solo un componente del rol del "lector real", mientras que para Eco ese "lector ficticio", dibujado en el texto, precisamente porque viene definido genéticamente, encarna la competencia solicitada al "lector real".

Un texto puede prever varios "lectores modelos", pero también puede hacer un trabajo de selección, prefiriendo, por ejemplo, aquellos que tienen una cierta competencia en una determinada materia, ya que seguro podrán hacer conexiones más significativas. En todo caso, la cooperación textual se lleva a cabo ante todo entre dos estrategias discursivas: una estrategia que se manifiesta con un conjunto de instrucciones, condiciones, autorizaciones, etc., y otra estrategia que se mueve obedeciendo a aquel conjunto de condiciones textualmente establecidas que satisfacen las potencialidades de un texto.

Hasta ahora nos hemos ocupado del lector modelo inscripto en el texto; pero el proceso hermenéutico quedaría trunco (especialmente en el ámbito bíblico) si -en términos de Ricoeur-al fenómeno del distanciamiento (característico de la escritura) no le siguiese la apropiación; o sea, si al "comprender" no le siguiese el "comprenderse frente al texto", el "exponerse" y, por último, el "perderse". Es decir, el diálogo entre "lector real" y "lector modelo" es absolutamente necesario para que se dé una auténtica comunicación. Es obvio que el "lector real" es muy distinto del llamado "lector modelo". No se identifican. Los "lectores empíricos" somos todos nosotros, cualquier persona que lea el texto en un momento determinado y en una situación concreta, mientras que el "lector modelo" -como ya se ha señalado- es el "lector-tipo" el que el texto prevé, más aún, el que el texto crea o intenta crear (de esto depende el éxito de la obra). Una obra puede postular, por un lado, una libre intervención interpretativa, mientras que, por otro, puede exhibir ciertas características que vinculan y/o regulan sus interpretaciones. Desde luego, el "lector empírico" es libre para aventurarse e intentar por su cuenta y riesgo todas las interpretaciones que quiera; sin embargo, debe ser consciente de que el mismo texto le pone límites y no aprueba cualquier interpretación temeraria. A través del "lec-

16 Eco, Sei passeggiate, 20-21. 
tor modelo", el texto establece sus propias reglas de juego, reglas que un "lector empírico" puede aceptar o no. Pero el éxito de la cooperación se realiza cuando el "lector empírico" respeta las reglas de este juego interpretativo.

\section{Modelo dialógico y hermenéutica bíblica}

El objetivo de esta segunda parte será comprender qué significa para la hermenéutica bíblica pasar al modelo dialógico. He aquí en una forma más bien esquemática cuáles son los efectos que se derivan de asumir estas nuevas premisas.

\subsection{La interpretación de un texto bíblico no ha de plantearse en términos de sujeto y objeto, sino en términos dialógicos}

Esta premisa indica que la interpretación no debe entenderse como si de una parte estuviera el texto(-autor) inspirado (dotado de autoridad divina e inmutable) y de otra, el lector-objeto que recibe la Palabra ya escrita, el espectador de las grandes obras de Dios. Desde el punto de vista dialógico, en cambio, la inspiración y la interpretación se entienden como un encuentro entre dos sujetos en diálogo: el horizonte del texto y el del lector se encuentran en una confrontación dialógica, movidos por el mismo Espíritu. El texto y el intérprete (la comunidad que interpreta y no solo el individuo) se ponen uno frente al otro, cara a cara. En el pasado, la polémica entre la teología católica y la protestante estribaba en la dimensión "objetiva" o "subjetiva" de la inspiración y de la interpretación y se acentuaba -también aquí voy a simplificar-el hecho de la Biblia ya en sí misma Palabra de Dios o el hecho de que llega a ser Palabra de Dios en la aceptación del creyente. Pero la inspiración debe repensarse en términos dialógicos. En una lectura comunicativa, un determinado texto bíblico es el punto de encuentro entre la acción de Dios y la del creyente: por una parte está el texto que no se impone, pero se pone en juego frente a los interrogantes del hombre "secular" 17 , y por otra parte también el lector adulto entra en el juego con sus parámetros de comprensión del mundo, buscando en el diálogo con

17 "Secular" en el sentido que le daba Bonhoeffer: no el ateo, sino el hombre creyente convertido en "adulto". 
el texto no una respuesta "tapagujeros" a sus problemas, sino una auténtica "inspiración" para su vida.

Lévinas expresa todo esto con la hermosa metáfora bíblica del rostro: "nosotros llamamos rostro a la forma en la que el Otro se presenta y que supera la idea del Otro en mí" ${ }^{18}$. Lévinas llama rostro a la suprema manifestación de la "alteridad". Decir rostro significa ciertamente decir cercanía y afinidad, porque es desnudez y presencia; pero también significa decir alteridad, irreductibilidad. El intérprete entra en diálogo con su rostro, y, por tanto, con su horizonte existencial, histórico y cultural, y se encuentra frente al rostro del texto. En ese recíproco respeto se puede iniciar entonces un diálogo, con la convicción de que en el rostro no está todo dado ni es totalmente previsible y mucho menos dominable. La tentación del hombre es la de englobar al Otro en vez de reconocer que él, en cuanto "otro", existe antes de mi propia iniciativa y de mi propio poder. Ha habido épocas en las cuales se ha buscado anular el rostro del intérprete, su libertad espiritual. Igualmente, han existido épocas en las que se ha querido anular la carga explosiva del texto en nombre de una interpretación acomodadora que leía el texto solo en una cierta dirección. Se necesita, en cambio, reconocer que la relación texto-lector es una relación dialógica, en la cual ninguno tiene derecho a imponerse arbitrariamente sobre el otro.

Esto conlleva tres consecuencias:

(1) La primera -de naturaleza más general-es que el discurso sobre la interpretación de un texto no puede prescindir del polo receptor. En efecto, la atención de los estudios tiene que trasladarse de la inspiración entendida como "sistema" dogmático entregado a la comunidad creyente (como un paquete) a la inspiración entendida como relación comunicativa en la cual la decisión interpretativa del receptor entra a formar parte del texto en causa (un paso ya iniciado desde el concilio Vaticano II que coloca el acento en la dirección dialógica que acabamos de esbozar).

(2) La segunda consecuencia de esta visión dialógica-de naturaleza más específicamente antropológica- hace referencia a que el hombre (todo hombre) no está nunca desprovisto delante de un texto, porque (lo decía ya Bultmann) el hombre, antes de estar situado "culturalmente", está situado "existencialmente"; antes de pertenecer a una determinada cultura, el hombre es "existencia". Es precisamente la inteligencia auténtica de su existencia la que el lector encuentra en el diálogo con el texto.

(3) La tercera consecuencia alude en particular al intérprete creyente. En esta óptica dialogal entre texto y lector no se ha señalado suficientemen-

18 LÉVINAS, Etica e Infinito, 49. 
te que el sujeto privilegiado del diálogo son los pobres. Los 'ănāwîm son los interlocutores privilegiados del texto bíblico: ellos son "el lector modelo" -según las categorías expresadas anteriormente- y, por lo tanto, el polo de pre-comprensión de la Biblia. ¡A los pobres se les ha dado la revelación del Reino! (Lc 4). Pero decir esto significa que son ellos el sujeto interpretativo, el "lector modelo" con el que los "lectores empíricos" tienen que confrontarse.

Frente a esto, podría surgir una objeción: ¿si quitamos el primado del texto no se corre el peligro de un subjetivismo interpretativo? En ausencia de una normatividad objetiva, ¿no se llega a una fácil identificación entre interpretación e invención? En otras palabras, si se destruye el primado del texto, ¡cualquier interpretación vale!

A esta objeción se puede responder-siguiendo a Ch. Theobald- que el texto bíblico es un texto inspirado e inspirante ${ }^{19}$. Decir que el texto bíblico es inspirado e inspirante significa decir que el texto no es un objeto terminado o definido, un objeto inmutable, sino en continuo progreso y en continua relación con quien lo lee. Sin embargo, esto no significa aceptar como válida cualquier interpretación; porque el lector competente sabe que con el texto no se puede jugar como un niño juega a hacer construcciones con los ladrillitos. La hermenéutica no es la combinación de piezas como mejor nos parezca o según lo que la fantasía nos sugiera, para obtener asî todas las soluciones que se buscan o se desean. Es verdad, ante un texto el "lector empírico" puede hacer todas las conjeturas posibles, pero al final estas son comprobadas sobre la base de la coherencia de la obra o -en términos pragmáticos- sobre la base de aquel entramado textual que se llama "lector modelo". Hay una estrategia textual que no permite al "lector empírico" cualquier interpretación, dado que el horizonte del "lector empírico" del siglo XXI debe entrar en diálogo con el horizonte del "lector modelo" presente en el texto. En eso consiste la competencia pragmática: un "lector empírico" se muestra competente cuando interactúa con las estrategias textuales, con el "lector modelo". Rizzi escribe:

La falsa objetividad de quien toma todo literalmente (como si las palabras fueran rocas que desafían inmutables, y no productos históricos del hombre) y la anti-objetividad de quien menosprecia la letra (como si las palabras fueran los piezas de una construcción infantil) llega al mismo resultado de liquidar la seriedad del esfuerzo hermenéutico... ${ }^{20}$

19 ThÉobald, “Seguendo le orme...", 71.

20 Rızzı, Letture attuali della Bibbia, 263. 
En la medida en que el texto expresa el "lector modelo" con el cual el "lector empírico" tiene que confrontarse, se puede hablar por supuesto de una cierta soberanía del texto; pero solo en el sentido en que el lector comprende que no puede hacer con el texto lo que le plazca. Así queda claro que solo en la confrontación de los dos horizontes se expresa la riqueza de la Palabra.

\subsection{El contexto de la interpretación no puede ser simplemente el semántico, sino que debe ser el pragmático}

Afirmar que el verdadero contexto es el pragmático (y no solo el histórico) significa ante todo sacar el concepto de inspiración y de interpretación de la estrechez del período histórico en el que a menudo se los ha limitado

Pensar -como lo hace, por ejemplo, Franzelin- que existía un tiempo de la Iglesia (el de los comienzos) en el que el carisma de la inspiración era un fenómeno "extraordinario" por estar vinculado al tiempo constitutivo de la Revelación, mientras que en los tiempos posteriores (incluido el nuestro) es "ordinario" porque a la Iglesia que sucede a la de los orígenes se le asegura una asistencia del Espíritu para conservar y desarrollar el depósito de la fe, resulta por lo menos engañoso ${ }^{21}$. Aparte de la dificultad histórica de distinguir el período inicial -concluido "con la muerte del último Apóstol"de los otros períodos y además del peligro que Ch. Theobald ve en el hecho de "minimizar nuestra contemporaneidad con la Revelación y la creatividad inherente a toda recepción, la cual no se puede nunca reducir solamente a un acto pasivo de salvaguarda" 22 , a mi juicio el problema desde el punto de vista pragmático es otro. Si la Escritura tiene la fuerza de informar y formar personas en situaciones y contextos diferentes, esto significa que el horizonte de privilegio y creatividad no puede quedar limitado al "contexto" inicial, mientras que los otros períodos desarrollan simplemente una función de salvaguarda. La creatividad es inherente a toda recepción y, por lo tanto, a todo contexto. Los inicios constituyen más bien el prototipo: lo que Dios realiza en todo momento, en todo lugar y con cada hombre y lo que el hombre hace cada vez que entra en diálogo con Dios en la lectura del texto.

Obviamente la Palabra de Dios que es la Biblia tiene un vínculo con la historia de Israel y con la historia de los orígenes y el método históri-

21 Sigo aquí a Theobald, "Seguendo le orme...", 56-59.

22 Theobald, “Seguendo le orme...", 59. 
co-crítico, desde sus orígenes, se ha distinguido como el guardián del texto y de su sentido histórico; pero ha descuidado la dimensión hermenéutica, que brota de la convicción de que el lector de hoy no es el espectador inerme de un objeto ya dado. El método histórico-crítico ha tenido y tiene todavía numerosos méritos, especialmente por su atención al desarrollo histórico de los textos y a su ubicación ambiental. Pero, al menos en sus manifestaciones más extremas, corría el riesgo de convertir a la Biblia en un libro hermenéuticamente cerrado e irrelevante. Principalmente, en estos últimos tiempos se ha visto la necesidad de pasar desde la consideración de la Biblia como una palabra estática -por estar asentada en una condición histórica precisa- a la consideración de la Biblia como una Palabra viva y actual. Es en la hermenéutica donde la Biblia exalta su eficacia vivificadora con relación a la existencia y al presente del hombre.

Ahora bien, el estudio del lenguaje con su función principal de carácter comunicativo ofrece un acceso más inmediato y, al mismo tiempo, más vivo a la relación que se establece entre autor y lector del texto bíblico. De ese modo, la Palabra de Dios llega a ser pregunta, apelación, exigencia... y no simplemente un conocimiento racional de los eventos. Si el texto bíblico se contextualizara solo históricamente, si tuviera valor solamente como libro de origen o como documento de fe de las antiguas generaciones, no tendría esa continua fuerza performativa/interpeladora que en cambio tiene para cada lector, de todo tiempo. En otras palabras, la fuerza inspiradora del texto encuentra al lector en todo tiempo; este a su vez, gracias al Espíritu, es capaz de progresar de una manera siempre nueva en el vínculo con el Verbo de Dios y con su Espíritu. De esta forma, el círculo hermenéutico que se produce en este diálogo incesante crea siempre una nueva percepción del horizonte inspirador y un crecimiento continuo de la Escritura. "La Escritura crece con quien lee" decía precisamente Gregorio Magno. Esto significa que la hermenéutica existencial de Bultmann, la secular de Bonhoeffer o la liberacionista de Gutiérrez tienen su razón de ser: las tres hermenéuticas redefinen pragmáticamente la relación entre el contexto histórico en el que el texto bíblico ha sido generado y los nuevos contextos que transforman el "para sî" del texto en un texto "para nosotros".

Regresamos al discurso crucial sobre las múltiples posibilidades de un texto, también en este ámbito del contexto. Frente a estas posibilidades que un texto posee de suscitar múltiples interpretaciones, el medioevo había ido a buscar una pluralidad de sentidos (literal, alegórico, moral, anagógico), lo que hoy se conoce como la ciencia de la comunicación y del lenguaje. 
En segundo lugar, una lectura pragmática, que hace partícipe al lector en el juego interpretativo, afirma con fuerza el carácter performativo del diálogo

Todos sabemos que a través del lenguaje no solo describimos las cosas, sino que actuamos, realizamos cosas. El lenguaje tiene una dimensión "agente" o "activa". John Austin ha pretendido expresar esta función con un título expresivo: How to do things with words? (Oxford 1962). Esto significa que cada discurso que realizamos, cada historia que narramos, cada enunciado que proferimos ${ }^{23}$ no tiene solo el objetivo de decir "cómo están las cosas", de constatar la verdad o la falsedad de las cosas, sino de llevar a cabo lo que el texto dice, narra o enuncia. Se trata en definitiva del lenguaje como acto performativo ${ }^{24}$. Todo esto tiene consecuencias importantes en el plano de la interpretación.

\section{Un ejemplo bíblico: las bienaventuranzas de Mt 5,1-12 y la pragmática}

A continuación analizaremos un texto bíblico: las bienaventuranzas de Mt 5,1-12. No partiremos tanto de una comprensión semántica del texto, sino de una serie de preguntas de tipo pragmático; por ejemplo: ¿qué función tienen para los lectores las bienaventuranzas puestas al inicio del Discurso del Monte (Mt 5-7)? ¿Qué estrategia se vislumbra a la luz de la disposición en la que se encuentran y de su específica formulación? ¿Qué tipo de acto lingüístico llevan a cabo estos macarismos?

\subsection{La posición estratégica de las bienaventuranzas}

La repetición a modo de letanía del término makárioi, puesto al inicio de cada enunciado, da un tono de alegría y bendición no solo a todo el texto en cuestión, sino al Sermón del Monte en su totalidad. Sin em-

${ }^{23}$ Lo mismo que con "Semiótica" e "Semiología" (cf. nota 2), también con "frase" y "enunciado" se ha creado una cierta confusión, como si los dos términos se fueran sinónimos. La confusión deriva también de las traducciones que se hacen de los términos ingleses: sentence (traducido con frase, pero también con enunciado) e utterance (traducido con enunciado y enunciación). En mi opinión, la frase está en el orden de la sintáctica; el enunciado, en el orden de la pragmática.

24 To perform en inglés significa "cumplir”, "realizar”, “llevar a cabo". 
bargo, justamente este inicio tan festivo plantea algunos interrogantes: siguiendo la lógica, los macarismos no deberían abrir sino cerrar el Sermón del Monte. Es extraño que un sermón, todo él configurado en torno a la exigente voluntad de Dios, inicie con afirmaciones como "Felices los pobres de espíritu, porque a ellos les pertenece el Reino de los Cielos; felices los afligidos...; felices los pacientes...; felices los misericordiosos...; felices los que trabajan por la paz...". Lo notaba asimismo Pinjas Lapide:

He pensado -a menudo- que en realidad las bienaventuranzas quedarían mejor al final del Discurso del Monte, como su expresión más fina, que concluye con la culminante promesa de "Alégrense y regocíjense entonces, porque ustedes tendrán una gran recompensa en el cielo ${ }^{25}$.

Pero una cosa es cierta: la repetición del lema makárioi -9 veces- introduce a los lectores en una atmósfera de alegría y bendición. ¿Cuál es su intención pragmática?

En este primer discurso, Mateo quiere presentar a la comunidad la radicalidad de las exigencias del Reino, pero no sin antes haber afirmado que el Reino es una gracia. Quizás sea esta la primera vez que se exprese en el evangelio según Mateo -y de manera tan tajante- la relación entre el indicativo y el imperativo que tanto atravesó las interpretaciones del Sermón del Monte y dividió también a las confesiones cristianas que siempre hicieron referencia a él. Poniendo al principio de un discurso tan radical y exigente las nueve bienaventuranzas, Mateo quiere invitar a los lectores a percibir, antes que nada, el carácter salvífico del anuncio del Reino y a comprender que la misma exigente voluntad de Dios es "Evangelio", "bella noticia". Se podría parangonar con los Diez Mandamientos. Igualmente ellos expresan la exigente voluntad de Dios, pero también inician con: "Yo soy el Señor, tu Dios, que te hice salir de Egipto, de un lugar de esclavitud" (Ex 20,2):

El Decálogo no empieza con un imperativo, sino con un indicativo: Solo la demostración liberadora del amor de Dios -dicen los rabinos- le da derecho a tratar de "tú" al hombre y ofrecerle cargar con el yugo del Reino de los cielos ${ }^{26}$.

25 LAPIDE, /l discorso della montagna, 49.

$26 \mathrm{lb}$. 


\subsection{La fuerza de los actos lingüísticos}

Surge entonces una pregunta de naturaleza netamente pragmática: ¿frente a qué tipo de actos lingüísticos nos encontramos en las bienaventuranzas? En las nueve bienaventuranzas no hay ningún verbo en modo imperativo, todos están en indicativo. ¿Se trata entonces de actos "representativos", que describen la realidad de las cosas tal como son, o estamos ante actos "declarativos" que cambian el estado de las cosas? Más aún, ¿tienen que ver con los actos "compromisorios" mediante los cuales Dios se compromete personalmente a hacer que el mundo se adecúe a las palabras de esperanza expresadas en las bienaventuranzas? ¿Cómo deben entenderse estos actos lingüísticos? ${ }^{27}$ Es importante saberlo, porque con la categoría de bienaventuranza, aplicada a situaciones de indigencia humana, se corre el riesgo de avalar a veces un estado de pasividad frente a condiciones que deberían haberse denunciado como conductas indignas del hombre. ¿La espera de un futuro de resarcimiento (en los vv. 4-9 los verbos están en futuro) no convierte el mensaje de Cristo en un opiáceo para el presente? Esta preocupación -que no es infundada, si uno piensa en las deformaciones históricas debidas a una hermenéutica errónea del mensaje cristiano- muestra ante todo una mala comprensión de los actos lingüísticos de las bienaventuranzas.

3.2.1. Todo lo que se ha dicho hasta aquí nos impulsa ante todo a reflexionar sobre el vínculo que este texto establece constantemente entre makarioi/ felices y las categorías de personas desprovistas desde el punto de vista humano o de cualquier forma insignificantes. Se trata de un elemento desestabilizante o paradojal, porque el lector sabe a la luz de la experiencia diaria que los pobres, los mansos o los perseguidos... no son "felices". Por ejemplo, hermanos de países en dificultad como los de Venezuela, Nicaragua o Haití que deben dejar su tierra para buscar trabajo en otros países ${ }^{28}$ -donde solamente sobreviven, porque se les paga un sueldo sin beneficios sociales ${ }^{29}$ - no son felices; la mujer indefensa que es víctima del machismo

27 Sobre la naturaleza y la clasificación de los actos lingüísticos, véase, por ej., el estudio de Obara, "Las acciones lingüísticas".

28 Según las estadísticas migratorias del mes de abril de 2019, hasta esa fecha estaban entrando a Perú diariamente entre 1000 a 1500 venezolanos en busca de mejores condiciones de vida. Igualmente, están entrando muchos nicaragüenses a Costa Rica en busca de trabajo. Lo mismo pasa con los haitianos que se trasladan a muchos países de Latinoamérica porque en su país hay mucha pobreza.

29 Lamentablemente en Perú se está aprovechando la mano de obra del migrante, cuya paga es un sueldo miserable. Además, se los califica de ladrones o de violentos. 
tampoco es feliz ${ }^{30}$. Felices son aquellos que tienen los medios para imponerse, que poseen fuerza y poder, y que atraen sobre sí mismos la atención del mundo.

La desestabilización que produce esta relación entre bienaventuranza por una parte y carencia por otra es intencional: quiere provocar en el lector un cambio. Las bienaventuranzas son "actos declarativos", que cambian la realidad. Se trata de una inversión de la perspectiva, según la cual la verdadera "piedra angular" de la comunidad mesiánica, el compás con el que miden los constructores de la Iglesia de Cristo, son precisamente ¡las piedras que el mundo descarta! La piedra descartada por los constructores llega a ser piedra angular.

Desde el primer discurso los lectores saben, entonces, que el Evangelio anunciado por Jesús será alternativo para las categorías mundanas. El mundo vive de sus ideas: el compás de los constructores del mundo no es la mansedumbre o la misericordia... Jesús subvierte las categorías: Las piedras rechazadas llegan a ser piedras angulares: el compás de Dios no es el compás de los constructores del mundo. Muchas veces la Iglesia se ha manejado con el compás de los constructores del mundo, según la lógica del poder y del prestigio. Muchas veces la Iglesia -lo decía san Bernardo hace nueve siglos- ha medido su fidelidad más con los criterios justinianos que con aquellos ofrecidos por el Sermón del Monte. Ha olvidado que sus cimientos se fundan sobre una piedra descartada por los constructores.

Jesús declara felices a algunas categorías de personas que comúnmente no lo son. Declarándolas felices, Jesús modifica el estado de las cosas, trastoca las categorías de la sabiduría humana según la cual los pobres, los afligidos, los mansos o los perseguidos son perdedores. Esto quiere decir, sobre todo, que las bienaventuranzas se han de leer desde la óptica del Reino que se hizo presente en Jesús. El Reino inaugurado por Jesús instaura otro orden, una situación nueva, según la cual en el primer puesto está "el Reino de Dios y su justicia" (Mt 6,33). Poniendo en primer plano a los pobres, a los mansos, a los misericordiosos... no se pretende ni mucho menos adormecer las conciencias, sino más bien introducir una contestación radical del orden jerárquico de una sociedad secular, para la que solo cuentan los ricos y los poderosos.

30 En varios países de Latinoamérica la mujer es víctima del machismo. Incluso hay muchos casos de feminicidio. Concretamente en Perú, desde enero hasta junio de 2019, 75 mujeres han sido asesinadas por sus esposos, por sus parejas o por cualquier otro varón. 
Jesús, en definitiva, declara la paradoja de Dios y de su Reino: los perdedores se convierten en beneficiarios de la salvación mesiánica. Exactamente lo contrario del adormecimiento de las conciencias, porque se trata de una contestación radical a las categorías del mundo. De este modo Mateo no está absolutizando una condición histórica ni vinculando a ella la alegría cristiana. Lo absoluto para Mateo no es la condición económica o social en la que una persona se encuentra, sino "el Reino de Dios y su justicia" $(6,33)$, con la inversión de criterios que este prōton del Reino provoca.

Si quisiéramos traducir todo esto en términos socioeconómicos, se debería decir que la reincorporación en el pueblo de Dios de los excluidos y los marginados forma parte esencial de la misión de Jesús y de la salvación cristiana (Mt 9,13). Se dijo -y yo estoy de acuerdo- que en la actual situación

... el aspecto más alarmante no es que algunos pueblos dependan de otros y algunos seres humanos de otros seres humanos... Ahora lo que sucede es algo mucho peor: los gobiernos ya no consideran a los demás como sometidos o dependientes, sino como excluidos. 0 sea, ya no cuentan más, no encajan en sus cálculos, ni en sus cuentas, ni en sus proyectos de futuro, ni menos aún en sus programas económicos, políticos o culturales. Esto, por ejemplo, es exactamente lo que está aconteciendo con la enorme mayoría de los países de África ${ }^{31}$.

Jesús instaura otro orden. No deberíamos olvidarlo.

3.2.2. Si bien los macarismos son actos lingüísticos "declarativos", porque cambian la realidad, hay que decir que son igualmente actos "compromisorios". Compromisorios -según la definición de Searle- son aquellos actos lingüísticos en los que el hablante se compromete a sí mismo a hacer que las cosas correspondan a las palabras que dice. En otros términos, al decir: "Felices los pobres..., los mansos..., los misericordiosos...”, ¡Jesús se hace portavoz de ese Dios que se compromete a hacer que esto sea verdad! Las categorías de los "pobres", los "misericordiosos", los "mansos"... son declaradas felices, porque Dios se compromete con ellos y a su favor, para establecer un nuevo orden, para instaurar su Reino. Los "pasivos divinos" que aparecen en las bienaventuranzas ("serán saciados, serán consolados...") apuntan a Dios como aquel que se compromete en primera persona: ¡Él es el artífice del cambio! Este compromiso de Dios al lado de los pobres los convierte en protagonistas de la historia y no en individuos sometidos. Todo esto deriva de la idea general que se tiene de un rey en el Medio Oriente Antiguo y también en Israel: su función no era la de permanecer imparcial,

31 CAStillo, I poveri e la teologia, 334. 
respetando el statu quo. Tampoco consistía en hacer justicia a los súbditos según sus méritos: más bien debía asumir la defensa de quien no sabía y/o no podía defenderse, de los pobres, de los huérfanos, de las viudas que no tenían garantías, puesto que no poseían derechos. Por tanto, la condición ideal del rey no era la neutralidad, sino la asunción de responsabilidades con relación a los "pobres". Dios se compromete con los pobres y, por ello, llama a los discípulos y a los creyentes también a preocuparse por ellos.

\subsubsection{He aquí otro aspecto fundamental del Sermón del Monte: no solo} Dios es responsable de estas categorías de personas; también el hombre tiene que asumir su responsabilidad. Se trata, de alguna manera, de una tarea que el Mesías Jesús presenta a sus discípulos.

De hecho, en la gramática semítica, el verbo no se clasifica en función del tiempo (presente, pasado o futuro), sino según que se refiera a la acción como "completa" o como "incompleta". El futuro revela una acción incompleta, en devenir, porque el tiempo inacabado es un presente en devenir. Por eso, las bienaventuranzas en general están expresadas en futuro ("serán saciados, serán consolados, obtendrán misericordia"). El presente en devenir es el espacio de la responsabilidad del hombre: es el espacio del obrar humano, entre el presente de Dios y el futuro inacabado de la justicia humana. Es el tiempo de la responsabilidad que se extiende entre la promesa ya presente instaurada con el Reino de Dios y el futuro cumplimiento, cuando los afligidos sean consolados y los mansos hereden la tierra. El cristianismo es exactamente lo contrario de una doctrina "opio de las masas". El verdadero cristiano se involucra, debe hacer aquello que declara o proclama ${ }^{32}$.

Mateo es el evangelio de la ortopraxis y no puramente de la ortodoxia (lo había intuido muy bien la teología de la liberación, aunque esta partiera más bien de Lucas). Muchos ortodoxos se presentarán aquel día y dirán: "Señor, Señor, ¿no hemos profetizado en tu nombre? ¿Y en tu nombre no hemos expulsado demonios? ¿Y no hemos hecho muchos prodigios en tu nombre? Pero entonces yo declararé: "Nunca los he conocido. ¡Aléjense

32 La responsabilidad que deben asumir las personas en Latinoamérica con relación a las bienaventuranzas es denunciando las causas de la pobreza. Gutiérrez indica que la pobreza es causada por la injusticia, por la explotación, etc. En este sentido, el teólogo señala que el compromiso cristiano es ser solidario con los pobres. Pero no se puede ser solidario con ellos si no se lucha por erradicar la pobreza material (cf. GutiérREz, Teología de la Liberación, 381-386). Actualmente, una de las causas de la pobreza es la corrupción, que se ha asentado en varios países de Latinoamérica y del mundo, la cual permite que los pobres no tengan acceso a los servicios básicos, que no vivan un auténtico desarrollo humano y espiritual. De continuar así, los pobres siempre quedarán postergados. 
de mí, ustedes que obran la iniquidad!” (Mt 7,22-23). En esto, la teología de la liberación tenía perfectamente razón: ¡la praxis es el lugar hermenéutico de la fe! Y es importante comprenderlo, si queremos ser fieles a aquella bienaventuranza que resume y contiene todas las demás: “¡Felices los pobres en espíritu porque de ellos es el reino de los cielos!".

La parábola de Mt 25,31-48 presenta un rey que proclama: "Tuve hambre y ustedes me dieron de comer, tuve sed y me dieron de beber, estaba desnudo y me vistieron...". En este texto, lo que define el obrar como "justo" no es la relación con una determinada "ley formalmente cristiana". En la declaración del rey y en la respuesta de aquellos que son juzgados se repite una lista de seis obras de misericordia que naturalmente son solo ejemplares ${ }^{33}$ : es el cumplimiento de esas obras lo que decide el juicio. También dentro del judaísmo tenemos textos que testimonian un programa similar. En Sotá 14a tenemos un dicho de Rabbi Chama' bar Chanina', que comenta Dt 13,5:

\begin{abstract}
“Ustedes seguirán el Señor su Dios” de esta manera: ¿Puede un hombre seguir verdaderamente a Dios cuando el mismo libro dice que el Señor tu Dios es un fuego que consume? Pero eso significa que tienes que seguir la conducta de Dios. Como Dios vistió a los que estaban desnudos (Adán y Eva), tú también viste a los que están desnudos; como Dios ha visitado a los enfermos (Abraham), tú también visita a los enfermos; como Dios ha consolado a los afligidos (Isaac), tú también consuela a los afligidos; como Dios enterró a los muertos (Moisés), tú también sepulta a los muertos.
\end{abstract}

3.2.4. Es evidente que en el judaísmo no se trata tampoco de un simple programa ético, carente de tensión teológica, porque las obras de misericordia también en el mismo judaísmo constituyen una imitatio Dei. Sin embargo, el texto de Mt 25,31-46 sigue siendo único. En la historia de las religiones no existen páginas análogas a esta, en la que el juez se identifique con los más miserables de entre los hombres, por lo que el destino eterno de un individuo se decide en función del comportamiento que se tenga hacia ellos. Por tanto, la novedad no consiste solo en la imitación de Dios, sino en el definir la relación con Cristo sobre la base de la solidaridad con los pobres de la tierra.

En esta página Mateo nos presenta una nueva percepción de la realidad: los discípulos quieren conocer los signos del fin y de la venida ( $p a-$ rousía) del Hijo del Hombre (Mt 24,3). Jesús, en cambio, a lo largo de todo el discurso de los capítulos 24 y 25 los reconduce a la percepción de $s u$

33 Dar de comer a los hambrientos, dar de beber a los sedientos, acoger a los forasteros, vestir a los desnudos, visitar a los enfermos y visitar a los presos. 
presencia en la historia: los hambrientos, los sedientos, los prisioneros... son el templo donde Cristo está presente. Se trata de una nueva percepción del Dios-con-nosotros (cf. Mt 1,23; 28,20). El Rey-Juez ejerce su autoridad en la defensa de los pobres: en este juicio, la causa de los pobres es su propia causa, el destino de los pobres es su propio destino ${ }^{34}$.

Ciertamente se interpretaría mal a Mateo si se entendiese el juicio final de Mt 25 como la afirmación de un cristianismo definido esencialmente por una "ética filantrópica". Pero ciertamente resulta de una enorme importancia teológica que aquí Mateo concentre la presencia de Dios no en el templo ni tampoco exclusivamente en los representantes plenipotenciarios que hablan en nombre de Jesús (cf. Mt 28,20) sino en los pobres necesitados de ayuda. En lugar de interesarse por los derechos de la Iglesia, Mateo plantea aquí como criterio último de juicio la responsabilidad por los pobres. Como Iglesia, estamos llamados a redescubrir precisamente una teología y una ética de la responsabilidad. ¡Esta es la hermosa y seria provocación de las bienaventuranzas!

\section{Bibliografía}

Barthes, R., Le bruissement de la langue, Paris 1984.

Berge, K. L., "Communication”, en J. L. Mey (ed.), Concise Encyclopedia of Pragmatics, Oxford 1998, 140-142.

Bianchi, C., Pragmatica del linguaggio, Roma - Bari 2003.

Castillo, J. M., I poveri e la teologia. Vita, libertà, utopia nella teologia del terzo millennio, Assisi 2002 [or. Los pobres y la teología: ¿qué queda de la teología de la liberación? (Cristianismo y sociedad 49), Bilbao 1998].

Eco, U., Sei passeggiate, Milano ${ }^{6} 2005$.

GrICE, P., Logica e conversazione. Saggi su intenzione, significato e comunicazione, Bologna 1993.

Grilli, M. - Guidi, M. - OBARA, E., Comunicación y pragmática en la exégesis bíblica (Evangelio y Cultura 6), Estella 2018.

Gutiérrez, G., Teología de la Liberación, Salamanca 1975.

ISER, W., Der implizite Leser. Kommunikationsformen des Romans von Bunyan bis Beckett, München 1972.

LAPIDE, P., Il discorso della montagna, Brescia 2003.

LÉvinas, E., Etica e Infinito, Roma 1984 [or. fr. Ethique et Infini, Paris 1982].

34 Tomado de Mello, Mateo, 438. 
Mello, A., Evangelo secondo Matteo, Magnano 1995.

Obara, E., "Las acciones lingüísticas", en M. Grilli - M. Guidi - E. Obara, Comunicación y pragmática en la exégesis bíblica (Evangelio y Cultura 6), Estella 2018, 77-105.

Rizzi, A., Letture attuali della Bibbia, Roma 1978.

Sartre, J. P., Che cos'è la letteratura, Milano 1996.

SEgRe, C., Avviamento all'analisi del testo letterario, Torino 1999.

Theobald, Ch., "Seguendo le orme..." della Dei Verbum. Bibbia, teologia e pratiche di lettura, Bologna 2011.

VIla-Matas, E., "Si sente l'esigenza di un nuovo patto tra chi scrive e chi legge", Il Sole 24 ore. 02/10/2011, https://st.ilsole24ore.com/art/cultu$\mathrm{ra} / 2011-09-30 /$ sente-esigenza-nuovo-patto-121237.shtml?uuid=AaZnMo8D\&refresh_ce $=1$ [consulta: el 28/01/20]

[recibido: 21/08/19 - aceptado: 12/01/20] 